\title{
Condenados sin proceso: la condena de K. y Ben Larbi
}

\author{
Óscar Gerardo Alvarado Vega \\ Escuela de Estudios Generales
}

\section{Resumen}

Universidad de Costa Rica

Planteamos una lectura comparada a partir del sema proceso en las novelas Condenado sin proceso, de Nacer Wabeau, y El proceso, de Franz Kafka; en tanto, en ambos textos, el juicio y la condena surgen como imposiciones contra sujetos inocentes, incapaces de hacer valer su derecho de libertad. Los personajes pasan por el filtro de un castigo injusto y a todas luces dirigido a imponer penas sin asidero de verdad.

Palabras claves: proceso, castigo, juicio, condena, inocencia

\section{Abstract}

We propose a compared reading from the topic "process" in the novels Condenado sin proceso, by Nacer Wabeau, and El proceso, by Franz Kafka. While in both novels the judgement and the sentence arise as imposition against innocent subjects, unable to assert their right of freedom, they go through an unfair punishment filter, which in all lights directs the imposition of the penalty without basic truth.

Key words: process, punishment, judgement, condemned, innocence 
$\mathrm{E}$ n la novela Condenado sin proceso, el tema de la represión ante la disidencia o la diferencia de ideas religiosas, así como de ideales religioso-políticos, establece el conflicto que desata la radicalidad de posiciones fanáticas. Este texto de 2015 viene a establecer una nueva dimensión en el hacer temático-literario de nuestro país. Nacer Wabeau nos lleva de la mano por un mundo donde los personajes son vejados, violentados y encuentran la huella de un terrorismo aplicado sobre ellos.

El título alude, de manera velada, a El proceso de Franz Kafka, novela paradigmática de la literatura universal, lo cual fundamenta la comparación entre ambos textos. La condena de Josef $\mathrm{K}$., carente de un proceso que defina su culpa, es la imposición arbitraria de una ley que deslegitima la palabra del condenado y que lo acecha, lo reprime y lo condena, tal y como ocurre en la novela de Wabeau.

Temas fundamentales aparecen en esta historia: la tortura, el terrorismo, la vejación, el irrespeto a los derechos del otro, así como la defensa de ideales fanáticos de carácter recalcitrante que se convierten en el claro paradigma de una posición maniquea, en la cual el bien y el mal son asumidos desde posiciones ambivalentes pero nunca en diálogo. El personaje principal, Ben Larbi, es el símbolo de una sociedad que sufre la represión y la amenaza de guerra a partir del hecho de constituirse en sujetos marcados por acontecimientos sociohistóricos conflictivos y trágicos:

En el fondo, la historia de Ben Larbi se confunde con la historia de su pueblo y probablemente de toda la humanidad que se halla frágil e indefensa ante la amenaza terrorista y las nuevas formas de atentados estremecedores. Y lo más inquietante es que las armas de destrucción masiva están al alcance de cualquiera. Varios hechos son de todos conocidos. Antes de esta trágica historia que vamos a conocer, Omar pensaba que el choque de civilizaciones era un debate entre algunos intelectuales, que pretendían pronosticar los conflictos pos caída del Muro de Berlín. Fomentaban polémicas con el fin de sembrar la semilla del odio entre los pueblos. Para ellos, el fin de la historia había llegado. Sería un choque brutal a escala global entre la civilización occidental y la barbarie islámica, como jamás se había visto en la historia. La lectura de ese tipo de especulaciones nunca lo había convencido, y solo las leía por obligación, con el propósito de fundamentar sus opiniones. (Wabeau, 2015, pp.14-15)

Por otra parte, el toque de queda, en medio de la ciudad en la cual vive y sobrevive su familia, pone en evidencia el riesgo de muerte. De allí que la muerte funcione, aun cuando parezca tautológico, en un riesgo que parece no ceder un ápice en el entorno de la novela. La opresión sobre los sujetos que deambulan por el texto, en relación con Ben Larbi y los suyos, evidencia la dificultad de sobrevivir en un espacio de represión permanente. Por tal motivo, la religión y la política parecen en ocasiones no tener distinción alguna en medio de lo que ocurre:

-C' est des Chumata qui gouvernent ce pays (Son sucios los que gobiernan este país). Y estos barbudos, iEstado islámico o la guerra contra todos! ¿Quién gobierna a la religión? ¿Por qué no practican su religión y dejan la política 
para los políticos? Existen hombres capaces y honrados en nuestro país. Hay que hacer como los europeos, separar la política y la religión. Esta es la solución. (Wabeau, 2015, p.22)

La libertad se ve coaccionada en tanto marca un potencial peligro cuando las voces disidentes, o al menos aquellas que emiten criterios diferentes al del discurso de poder establecido, emergen con discursos contestatarios o no correspondientes con los de los grupos de poder o represores, tal y como ocurre con el oficio de periodista ejercido por Omar Ben Larbi, quien debe efectuar su labor desde la clandestinidad. Su trabajo, en tanto otredad para los detentadores del poder, lo convierte en sujeto peligroso, aun cuando esta misma otredad sea aplicable desde su lugar vital, desde su propio entorno en relación con aquellos.

Se enmarca el rechazo a las políticas radicales que degeneran, no en respeto, sino en imposición, en violación y que construyen y sobredimensionan las diferencias que dan por resultado la otredad impositiva y el irrespeto al violentado.

No es casual la existencia de discursos que establecen una especie de perennidad de conflictos que terminan por desangrar al pueblo y lo coaccionan:

- No, no, hijo mío, no es nada grave aseguró Da Lhocine -, yo también te tengo mucho respeto... Ustedes los jóvenes no saben cuánto sufrimos durante la Revolución para vivir dignamente en un país libre. Pero en aquel entonces era una guerra con objetivos claros: luchábamos contra el sistema colonialista francés, sin confundir las cosas, no odiábamos la cultura francesa ni matábamos a cualquiera. Claro está, como en todas las guerras, hubo errores... Pensamos que finalmente podíamos construir nuestro país y vivir en paz... Y ahora, treinta años después, el pueblo entero ha sido tomado como rehén, entre la furia de los barbudos islamistas y el poder con su dictadura disfrazada de democracia de fachada... No queremos ni un Estado islámico ni un Estado policial... Soñamos con algo mejor... A los de mi generación nos duele ver la destrucción de nuestro país... ¡Felices mis amigos difuntos! Por lo menos no ven esta nueva barbarie. (Wabeau, 2015, pp.34-35)

Estos conflictos religiosos no establecen diálogos, no posibilitan su existencia; por el contrario, dan pie a exacerbaciones que resultan en el irrespeto al otro. El desgarramiento a lo interno provoca marginalidad, destrucción, muerte, soledad y retraso ante la imposibilidad de lograr un país competitivo que se queda en la pesadilla interna de la guerra.

El símbolo conformado por los rostros barbudos es la pesadilla del pueblo, la esfera de dolor y de vejación a que se ven expuestos. Las pesadillas que sufren algunos durante el proceso mismo de insoportable realidad los llevan a vivir lo intolerable, no solo en la vigilia sino también durante el periodo de sueño. Es el despojo en la propia tierra, en el país que los ha visto nacer, en donde el símbolo de figuras antropomorfas da cuenta de lo que representa el dolor de sentirse extraño en aquel lugar que les pertenece:

Azidane le contó su pesadilla, bebiendo el agua a grandes sorbos. Le dijo que estaba en un hermoso jardín florido, lleno de árboles frutales, con un riachuelo de 
aguas cristalinas y que se inclinó para lavarse las manos, refrescarse la cara y beber un poco. En eso, dos seres velludos, medio humanos, medio animales, de apariencia gigante, lo abordaron y le dijeron que el riachuelo tenía dueños y que él no tenía derecho de andar por allí. Trató de irse sin defenderse. Pero uno de ellos le recordó que con solo entrar en el jardín ya era culpable. No tuvo tiempo de decirles que no sabía cómo había llegado al jardín, solo estaba por allí, por azar, cuando el otro lo agarró y comenzó a estrangularlo...

- Entonces grité - concluyó Azidane, volviendo a la calma poco a poco.

- Es una pesadilla. Hay que tratar de dormir. Cualquier cosa, me llamas.

- Gracias, amigo mío. No quiero estorbar tu sueño, me da vergüenza, pero desde hace semanas, no sé cómo evitar las pesadillas.

- Tranquilo, tranquilo, Azidane, estás en tu casa... (Wabeau, 2015, p.50)

Los preceptos radicales de carácter religioso parecen construir ideas diferentes de Dios, leído e interpretado desde diversos ámbitos, lo cual da como resultado el uso y abuso del discurso religioso en provecho de ideales políticos y fanáticos. Es el caso de los velos con los cuales deben cubrirse las mujeres, para evitar tentar a los hombres, según rezan algunos de los preceptos establecidos, ante los cuales Omar y los suyos manifiestan su disconformidad. De igual manera el vino, la música occidental, el uso de drogas, el uso de algunos idiomas no oficiales, etc., atentan contra lo que el gobierno define como lo establecido, en términos de "pureza", para los habitantes del país. Recurrir a estas manifestaciones es violar lo "sagrado", pecar y merecer el castigo correspondiente.

De tal manera, la novela plantea la crítica, lo insoportable de lo que representa el proyecto y quizás UN proyecto ideológico-religioso. La religión, desde tal punto de vista, no es acercamiento, no es diálogo, sino más bien radicalización de las diferencias. La exacerbada inclinación a lo establecido, a la historia y a las costumbres encuentra espacio de conflicto y de lucha con los cambios venidos desde fuera, que ponen en entredicho "la pureza", lo establecido, lo existente, la historia misma. Los cambios vienen ejercidos por posiciones y discursos "demoníacos" que atentan contra las normas vigentes. La perversión "viene desde afuera", el demonio está invadiendo. La reacción, aun a costa de la muerte, toma lugar en el texto.

Las revoluciones y sus limitaciones son otra de las tantas venas de lectura que dimensionan la novela. El cuestionamiento de Omar en relación con estas da lugar a su frustración ante los objetivos que fracasan cuando los cambios necesarios no llegan.

Por otra parte, las mezquitas y las salas de cultura son hervideros de discurso en los cuales se construyen las posiciones radicales que dan margen a los conflictos. Cientos de estas confluyen a lo largo del país: se dan el pensamiento y el diálogo entre quienes adversan la arbitrariedad del gobierno en ejercicio, mientras el sistema educativo construye escuelas, colegios y universidades basados en sistemas obsoletos, retrógrados que, lejos de beneficiar el progreso, impiden la dinámica necesaria y frenan las posibilidades indispensables señaladas por Omar y sus amigos.

El padre de Omar experimenta en su momento un cambio de filosofía existencial y adquiere una visión 
pesimista. Su fe en el hombre se desvanece mientras se acrecienta su desencanto en relación con el mundo actual:

- Natura, natura, natura - repitió el padre -, todo cambia menos la naturaleza humana. Yo dudaba entre Rousseau, que defendía la bondad natural del hombre, y Hobbes, que insistía en la crueldad natural...

- No sé - replicó el padre -, antes me inclinaba por Rousseau, ahora, estoy casi seguro de que Hobbes acertó con la idea de que el hombre es un lobo para el hombre. (Wabeau, 2015, p.67)

Los cambios que se dan acrecientan la muerte y la tragedia que revisten a la población argelina. La necesidad de una salida palpita en el corazón del pueblo, mientras el mundo experimenta violentas transformaciones hacia la muerte y la degradación del ser humano. La guerra que desangra a su gente ha de convertirse en una especie de maldición para Omar, en la medida en que luego, reubicado y con el paso del tiempo, cuando su vida empieza a manifestar un giro importante, los atentados del $11 \mathrm{de}$ setiembre rompen nuevamente hacia el desequilibrio. El texto nos va planteando, en el proceso de los años que va describiendo la novela, la construcción del infierno personal que sufre Ben Larbi, mientras la imposibilidad de enfrentar la rudeza de la situación lo marca negativamente. El éxodo de argelinos constituye la más fuerte herida que Ben Larbi enfrenta, mientras el mundo se vuelve caótico para él en esos momentos.

La barbarie y la muerte van de la mano, mientras hombres, mujeres $\mathrm{y}$ niños se ven amenazados. La disidencia de ideas y el miedo al otro, al prójimo, al inmediato, toman un lugar preponderante en la sociedad de Omar Ben Larbi. La muerte se extiende por doquier. El asesinato de los monjes se convierte en la condena e indignación hacia la barbarie que termina, sin embargo, por imponer su voluntad. En medio de tal ambiente, la familia de Ben Larbi, y quienes piensan como él, corren el riesgo de enfrentar las consecuencias en caso de que la voz se convierta en objeto de persecución y castigo. La verdad es la exigencia de un pueblo que termina por no saberla.

Todo lo anterior deriva en el concepto de país como prisión a cielo abierto, la peor de las metáforas que golpean el devenir de los personajes, mientras la catástrofe va tomando lugar paulatinamente y los ahoga, los reduce, los enajena en su propia Nación. Con todo y ello, algunos optan por la emigración clandestina, aun cuando, como lo señala la novela, las personalidades y los de edad avanzada no tengan problema para ello. Farida y Azidane, y los jóvenes en general, sufren paradójicamente la condición de ser jóvenes, por lo cual emigrar no resulta fácil.

La violencia, mientras tanto, adquiere tal grado de presencia que incluso los juegos de los niños tienen como asidero el discurso violento de la guerra, en el juego de la vida y la muerte. El matar al otro se convierte en la consigna de estos niños, mientras la preocupación de los mayores aumenta ante el frenesí incontenible de las grandes diferencias que van quebrantando no solo el país, sino a los propios hombres y mujeres que ven sus vidas amenazadas. En los juegos, la muerte termina por asimilarse de tal manera que llega a convertirse en parte intrínseca del hacer lúdico. La cultura de la violencia, como apunta Omar, termina por enquistarse con plena fuerza en la cotidianidad. 
De las situaciones anteriores se desprende como corolario la idea de la esclavitud del alma y el cuerpo, la violación plena, la desposesión, el espíritu derrotista, la desazón ante lo que ocurre y que parece no tener salida. El grito de Djamila, en cuanto a la forma de vestir y tener que ocultar su cuerpo y su belleza, redunda en el despojo total. Es la carencia de libertad, es la represión llevada a su máxima expresión.

El destierro parece ser la mejor de las soluciones, en muchos casos, ante el riesgo inminente de la muerte, el ajusticiamiento, el secuestro. El miedo toma lugar en las calles y las casas. La violencia campea por doquier. Para Omar, como símbolo de los jóvenes profesionales de su Nación, la idea del exilio, el distanciamiento de su familia, amigos y país, y la soledad que comporta vivir en otro lugar privado de los seres amados, termina por causarle un desencanto que lo sume en la desesperación y la derrota. Es, en definitiva, el sometimiento a los preceptos de los opresores.

Todo ello ocurre debido al ansia de poder y la degeneración de los ideales. La corrupción se entroniza en el poder en el Gobierno de Argel. La muerte del Presidente Boudiaf representa el castigo a los que no transigen con los dictados impuestos. A este se lo nombra, pero se niega a formar parte de lo que representa la cúpula detentadora de un poder criminal, por lo cual se lo manda a matar. La crítica ante lo que representa la impunidad de los terroristas posicionados y posesionados en las altas esferas de conducción gubernamental es uno de los ejes fundamentales de la novela, en el marco histórico que va recreando el autor. La muerte del poeta Wlid Al Kasba golpea el ánimo de Omar Ben Larbi ante lo que representan las voces emergentes y la barbarie que significa eliminarlas cuando contradicen los discursos imperantes. El poeta es degollado en su propia casa y quemada su biblioteca, con documentos invaluables. Se entroniza la barbarie, apunta Ben Larbi.

Ante lo que ocurre, la captura de Omar y su secuestro se convierten en una forma de presión al padre, para obligarlo a dimitir en su política de justicia. El soborno ante la amenaza de decapitación que pesa sobre su hijo, en caso de que el padre no renuncie a su puesto, es apenas un ejemplo palpable de lo que significa la radicalización de ideales degradados, convertidos en ideas que atentan contra la razón y construyen una locura social que desvirtúa las posibilidades de acercamientos y el respeto a la ideas y creencias contrarias.

La otredad es moneda corriente en el trayecto de los personajes a lo largo de la novela. La mismidad no se discute, sino más bien la imposición de lo que ya hemos acotado: la existencia del otro como una amenaza, como un riesgo, como un enemigo. El rechazo toma posesión y se posesiona y posiciona ante el otro. Ello sucede cuando los captores de Omar, en Argel, discuten entre ellos, mientras Ben Larbi los escucha:

Conversaban de las cosas de la vida. Una vez un terrorista le preguntó avergonzado a su colega:

- ¿Cómo puede un hombre casarse con una mujer que usa pantalones?

- Es un pecado - opinó el otro terrorista -. Es como casarse con un hombre, Dios nos proteja. - Dicen que en Europa hay mucha confusión, ya que no pueden reconocer quién es un hombre y quién una mujer. Dicen que incluso hay hombres que prefieren casarse con otro hombre. Y lo más grave es 
que en algunos países la ley lo permite. - Los europeos son degenerados. Por eso Dios los está castigando con el sida. (Wabeau, 2015: 114)

El discurso del grupo que adversa las posiciones de Omar intenta justificar sus actos, con la muerte incluso, si la promesa del Paraíso trae como resultado la defensa de sus ideales. La razón la ostenta siempre aquel que construye la verdad desde su posición discursiva. Tal es lo que ocurre con los adversarios al régimen y los defensores de este. Los discursos existen porque se contraponen y se antagonizan en la novela:

"Ningún musulmán honrado debe descansar en este mundo hasta la liberación de Palestina... En Arabia Saudita, debemos purificar los lugares sagrados profanados por la presencia de infieles de los Estados Unidos de América... Nuestros enemigos tienen misiles, nosotros tenemos la fe... El tiempo dirá cuál de las armas es más poderosa. Con la fe y la voluntad de Dios convertiremos sus naves en polvo...", decía el Jeque con un innegable don de orador. "Hermanos de la Uma al Islamia (Comunidad Islámica), os digo, la hora del gran yihad ha llegado, no habrá tregua antes de la purificación de nuestras tierras desde Indonesia hasta Marruecos. Habrá fuego y terror en las ciudades de los infieles hasta que dejen de chupar nuestro petróleo. A los gobiernos cómplices de los infieles prometemos dolor en dos mundos, la muerte en este mundo, el infierno en el otro. A nuestros muyahidine les serán reservados los lugares más deseados en el Paraíso, donde corren los ríos de miel y leche, donde podrán disfrutar eternamente de todos los placeres...". (Wabeau, 2015: pp.120-121)
El secuestro de Omar y su angustia ante la posibilidad de ser fusilado van minando su resistencia y construyen el miedo ante su propia muerte, pero también ante la posible muerte de sus familiares y amigos. Por lo tanto, su salida del país es un intento de liberación ante la presión ejercida sobre él y los suyos. El miedo campea por los rincones de su país.

Ahora bien, la desposesión del personaje, tras su exilio, da como resultado una suerte de "espíritu del extranjero" que radica en la soledad, en la nostalgia, en la tristeza, en la añoranza de la nación y la familia. Omar Ben Larbi se debate entre la posibilidad de un éxito que le va llegando laboralmente en otra nación y una distancia que lo golpea mientras el dolor lo atormenta. Su salida del país poco a poco le va granjeando una mejora en su condición de vida, aun cuando la separación de los suyos y la añoranza del regreso lo convierten en un sujeto marcado por la tristeza y el desencanto. Es similar a lo que ocurre con una de sus amigas, Marie, la cual hace manifiesto también su dolor:

Nuestros colegas franceses son amables, solidarios e indulgentes con nosotros. Pero me identifican como una extranjera. Y eso me recuerda que no soy de aquí. De modo que apenas se acabe el terrorismo vuelvo a mi país. Qué difícil es echar raíces en tierra ajena, hay algo inefable en el alma que me hace sentir atada a mi tierra natal. (Wabeau, 2015: 128)

El exilio deja una huella que lo sacude. Es la carencia de la patria, la salida forzada ante la injusticia y la arbitrariedad de algunos: 
Durante la pausa, el público se dio a un ir y venir en un ambiente de fiesta. Marie, Arezki y Omar se incorporaron a un grupo en la acera. Fue un placer encontrar a varios amigos de la universidad. Se abrazaron una y otra vez, se hicieron preguntas, se miraron a los ojos como para darse cuenta de que era cierto, estaban allí, cara a cara, hijos de la misma tierra, separados por la guerra, unidos en el exilio. (Wabeau, 2015:141)

Por otra parte, la clandestinidad, en la cual se mueve en algún momento Ben Larbi, también lo desgarra mientras ansía el retorno y el reencuentro con los suyos. El oficio de periodista lo obliga a actuar y desempeñarse casi en secreto, para poder ejercer de forma clandestina una labor que, por formación, elección y deseo, debería ser manifiesta ante los ojos de todos.

Mientras tanto, después de haberse ido a Estados Unidos a laborar, la lucha por un mundo mejor, que lo mueve como uno de sus principios vitales, se vuelve cuesta arriba cuando es enjuiciado por los acontecimientos del $11 \mathrm{de}$ setiembre. Ello constituye la asimilación de un pueblo, del cual se borran las diferencias para construirlo a partir de un mismo objetivo, de una única significación y con la marca del terrorismo asignada desde afuera, desde el otro. Lo que en principio se vislumbra como la realización de un sueño, o al menos la posibilidad cercana de serlo, se transfigura en la condena que recibe por el hecho de ser extranjero, leído e interpretado a partir de prejuicios que declaran un abierto desconocimiento hacia el argelino Ben Larbi, en este caso. Construido y definido como terrorista, se "convierte" en un sujeto signado por la barbarie de un gobierno que desconoce y construye "verdades" desde lo que también pasa a ser una especie de radicalismo ideológico.

Omar se "hace" en la ciudad de Nueva York, donde confirma su ser como argelino, pero con la posibilidad de interactuar en un mundo diferente, heterogéneo, multicultural. Ese mundo le brinda una perspectiva diferente, un carácter de globalidad ajeno en él hasta entonces, pero enriquecedor. En ese espacio de posibilidades, pero al mismo tiempo de prejuicios, halla la disyuntiva que implica su desencuentro en la nación que la ha dado asidero, no por él mismo, sino por el desconocimiento que se manifiesta en torno a la interpretación que de él se efectúa por parte de los demás. Con la tragedia del atentado emerge su propio infortunio. Deja de ser para convertirse en alguien más, a los ojos plenos de prejuicio de una nación aterrorizada. Ben Larbi ya no ha de ser el director de una empresa turística. Ahora pasa a ser el artífice de actos terroristas, ligados a figuras demoníacas, de las cuales él es una pieza clave, según las interpretaciones que se le endilgan en adelante. Del ser pasa a la apariencia, y de allí a la asignación impuesta de una identidad que él no se construye sino que le es impuesta. Ben Larbi es el terror. El proceso Kafkiano al cual hemos hecho alusión concuerda con el horror que le es asignado y que él mismo vive. Es figura demoníaca en un país que al propio Omar se le transforma en infierno. Las políticas de lectura impuestas sobre su persona lo desdibujan para convertirlo en otra cosa. Deja incluso de ser persona y se convierte en monstruo, en sujeto sangriento, y luego en criatura animalizada cuando sobrevienen las torturas para obligarlo a confesar lo que es una verdad 
construida desde afuera, a pesar de la inocencia que este defiende para sí. En ese proceso ser-parecer y parecer-ser, Omar Ben Larbi es cosificado y denigrado por completo.

Ben Larbi encuentra un mundo heterogéneo, multicultural, en donde las manifestaciones religiosas, como los Hare Krishna, los Testigos de Jehová, los Moonies, los cristianos, los musulmanes y otros, se hacen sentir cada una a su manera. La convergencia de ideas religiosas parece llenarlo en tanto expresión de libertad. Ello es parte del proceso de enriquecimiento que en Nueva York marca su devenir primero, pero luego se le convierte en otra cosa, que lo enajena y lo reprime. Posteriormente, con la caída de las torres, su mundo parece también venirse al suelo. La visita previa a estas con el fin de conocerlas como potencial turístico deriva en la tergiversación de ideales que procuran derrocar al gobierno estadounidense. De tal manera se lo ha de ver en adelante.

Se manifiesta una confluencia de religiones, cada una de las cuales manifiesta su búsqueda, su credo. Cada religión, ante sus ojos, es expresión de una visión de mundo, espiritual, que procura el mejoramiento del ser humano. En el fondo, si bien no se define a sí mismo como practicante, ejerce su propia espiritualidad basada en el respeto al otro. Tal respeto es el que solicita Omar para sí, para su pueblo, para su familia, para todos.

No obstante, el ataque a las torres gemelas y la barbarie terrorista, percibida desde la visión de mundo de Omar, cambia también su percepción con respecto a lo que hasta ese momento le representaba un cambio hacia una mejor condición. La visión de los aviones al estrellarse contra las torres redimensiona su visión con respecto a lo que pueda suceder en adelante. Lejos está de sospechar, sin embargo, lo que ha de acontecer poco después. La tragedia de lo que ocurre se convierte en suya, y responde al espíritu trágico también de su lucha interna y de la batalla de su pueblo y sus luchas históricas.

La novela manifiesta, por ende, la existencia de fuertes prejuicios de carácter religioso, ideológico e incluso de confusiones graves de carácter espacial, que terminan por convertir en terroristas a quienes proceden de este espacio, aun cuando haya diferencias palpables entre las diversas naciones que componen la región. El despojo de la condición humana para revestirlos de bestialidad, como se presenta en el diálogo entre dos neoyorquinos, grafica con claridad la lectura que se ejerce desde la distancia, desde el desconocimiento, con respecto a este otro que en adelante es la amenaza. El miedo se construye desde lo que se ignora y la desconfianza se hace superlativa cuando ese otro, la bestia como la llaman estos, atenta contra mi orden y mi espacio. La lectura de mi propio espacio de otredad hacia estos no emerge. No soy yo quien amenaza; es siempre el otro, que lo es por no responder a mi espacio de mismidad.

El terror de Omar, desde Argel, sus recuerdos, la confusión y el caos aparecen:

- ¡Ay, no sé qué decirte, Anita! - replicó Omar, tragó difícilmente saliva y prosiguió -: Cuando veo estas horribles imágenes de violencia, trasmitidas de forma instantánea en el mundo entero, me siento tan indignado, tan frágil y tan preso de un sentimiento de rebeldía interna, que no sé cómo expresarme. Es una tortura, todo mi ser se 
convierte en pena. Además del sufrimiento humano de que somos testigos en Manhattan, no puedo borrar los recuerdos del dolor causado por el terrorismo en mi país, allá por los años noventa. En Argel y en Manhattan las víctimas inocentes son seres humanos, que podrían ser cualquiera de nosotros. Creo que les he comentado el contenido de unas octavillas enviadas por una misteriosa organización llamada GAIFUS. No me acuerdo bien qué decían. Más tarde, voy a consultar los archivos en mi ordenador. Si no me equivoco, amenazaron: "Habrá atentados, fuego y terror en las ciudades de los infieles como nunca se había visto en la historia”. Es lo que estamos viviendo en Manhattan. (Wabeau, 2015: 232)

La existencia de prejuicios ideológico-religiosos comportan, paulatinamente, la desgracia que cae sobre Omar y los suyos. A la par de ello, el odio hacia este y sus allegados; las naciones, incluso de esta parte del mundo, se convierten en blanco de los prejuicios y a todos se los denomina con el apelativo de terroristas. La pandemia del miedo en Estados Unidos toma lugar y la neurosis que acarrean estos actos termina por desquiciar a los gobernantes de esta Nación y al país entero. Los dardos encuentran víctimas propicias y ello ocasiona el inicio de un proceso injustificado contra Omar Ben Larbi.

Los prejuicios, después de los atentados terroristas, confluyen en construir ideas paranoicas en relación con los perpetradores de tales actos y la construcción ideológica de nuevos terroristas afincados a lo interno de los Estados Unidos, tal y como le sucede a Omar Ben Larbi. La idea de la represión, el terror, los atentados, los talibanes, los violadores, la violencia, el odio contra Occidente y demás construcciones semánticas dirigidas a establecer un espíritu recalcitrantemente compuesto de rechazo y eliminación hacia todo lo que parezca árabe comienzan a tomar lugar en los Estados Unidos, mientras Omar se ve ubicado en el centro de los conflictos y se convierte en víctima propicia para este desahogo. Omar propugna por el diálogo y defiende su inocencia, mientras los tiros de venganza en pos de una figura clave del terrorismo se centran en él. Por ello Tarik, amigo de Omar, rechaza la idea de civilización que propugnan Europa y Estados Unidos, verdaderos artífices del terrorismo en otros momentos, cuando la permisibilidad de intereses propios les permite inventar alianzas y en otros momentos referir a causas injustificadas para el mundo si son provenientes de otras naciones. El extremismo de ambos lados, como menciona Tarik, ciertamente existe, por lo que se evidencia el manejo de intereses de poder en uno y otro lado. Por ello, de la noche a la mañana, Omar se convierte en terrorista, sin que pueda explicar el proceso mismo que provoca lo que le está sucediendo. El apego a su inocencia es leído como cinismo terrorista. Mientras la muerte es lo que más lo aterroriza en algún momento; en otro, se convierte en anhelo si ello le permite una salida a su tormento.

Aunado a lo anterior, se inicia el proceso de persecución contra Ben Larbi. La investigación que se inicia en su contra tiene como punto de partida la condenatoria inmediata, más que el establecimiento de una verdad. Ante los ojos de los investigadores, de los detectives, del pueblo en general, Ben Larbi es culpable por el solo hecho de no ser 
estadounidense, sino argelino; su origen y su procedencia lo ubican estratégicamente en el lugar de los atentados.

El odio hacia este, por parte de quienes en principio lo miran con simpatía, da cuenta del desconocimiento que se teje alrededor suyo en cuanto a sus ideas y sus inclinaciones vitales. Es desfigurado desde un discurso enfermizo que trae caos y confusión:

- No es mi intención herirte, Omar; pero, tengo que decirte que ayer, alguien dijo: “¿Cómo podemos distinguir a un terrorista islámico?” Otro le contestó: "Tenemos a uno de ellos en el edificio". (Wabeau, 2015: 244)

Así, la vigilancia se convierte en manifestación enfermiza y degradante para Omar y quienes como él sufren los prejuicios de ser leídos e interpretados desde la concepción deformante y tergiversada derivada de la paranoia del momento. La vigilancia, una suerte de panóptico foucaultiano, se ceñirá con la vida de Omar y quienes como él son interpretados desde el lugar del otro.

A lo largo de su estadía lejos de su familia, Omar va elaborando una serie de cartas enviadas por correo electrónico que terminan por convertirse en verdaderas reflexiones vitales, en cuanto a la vida, la soledad, la muerte, la angustia, el triunfo, el trabajo, todo lo que lo rodea. Son una especie de estribillo en cuanto a lo que representa su ser, su visión de mundo, su relación con el entorno:

¿Cuál es la diferencia entre las declaraciones extremistas del mandatario de la Casa Blanca y las amenazas del fundador de Al Qaeda? ¿Podrán los fanáticos de ambos lados cegarnos con las mentiras? ¿Podrán incendiar al mundo con sus discursos? ¿Podrán distorsionar las religiones, invocar a Dios y matar en su nombre? ¿Podrán enmarañar sus intrigas?... Mas, nadie puede impedirnos pensar diferente $\mathrm{y}$ manifestar abiertamente nuestra indignación. (Wabeau 2015: 252)

Luego viene el proceso como tal, la pérdida, la lucha, la carencia, el esfuerzo por no ser derrotado en su dignidad, su camino de degradación y su intento por mostrar la inocencia de su condición. Como Joseph K., enfrenta la persecución sin poder demostrar su inocencia, sin poder conocer abiertamente las razones que lo culpan:

Amigo mío, no me vas a creer si te digo que me han tratado de MAT; es decir, Musulmán Árabe Terrorista. Hasta mis vecinos, que me saludaban con respeto, ahora me miran de reojo como si yo fuera sospechoso, como si yo representara una amenaza a sus vidas. Claro que me duele; como a todo ser humano, las injurias dejan heridas. Pero, ¿qué voy a hacer?, así soy yo, tiendo la mano a los que me ofenden y los invito a conocernos... No, no es cobardía, sino resistencia pacífica. (Wabeau, 2015: 253)

La captura y el encierro dan cuenta de lo que representa la enfermedad paranoica de un juzgamiento sin pruebas; es El proceso de Franz Kafka, la condición criminal de quien no lo es, pero es despojado de su posibilidad de defensa. Como la novela lo indica, su captura le resulta un calvario, pues es atrapado al salir del hotel y, después de esto, inicia su condena ante la cual no tiene posibilidad de defensa. En ese momento se halla en el Reino Saudí, producto de un viaje de 
trabajo. El tormento inicia con el despojo de su personalidad, para ser reidentificado en otra esfera. Los vínculos con el terrorismo internacional le son asignados ipso facto, ante la incredulidad del propio Ben Larbi. La captura implica el error, el riesgo de tortura que comporta la situación degradante a la cual se ve sometido y las consecuencias nefastas que se ciernen en torno a él. En Kafka, la visión absurda del personaje se ve permeada por una acusación sin asidero; lo mismo ocurre en la novela de Wabeau, en la cual Ben Larbi sufre las consecuencias de un crimen del cual es inocente. Esa idea de la fatalidad que circunda ambos textos termina por enlazar en las dos novelas la sensación de un mundo sin asidero, revestido de un absurdo, como hemos señalado, que golpea el devenir de los personajes y los reduce por completo. Ese vacío existencial que cae sobre los personajes en las dos novelas produce la idea de un caos existencial que escapa de las manos de aquellos, que los arrastra y los sume en la derrota.

Sin salida, aparecen el encierro, la condena que se avecina, la pena de ser juzgado sin cargos. La imposición de cargos, a pesar de la inocencia de Ben Larbi, y la invención de su ligamen con la yihad completan el cuadro siniestro que golpea su realidad. Mientras tanto, la degradación a la que se ve sometido se manifiesta cuando, durante uno de los tantos interrogatorios, uno de los gorilas, según el texto, lo impele a firmar; ante la negativa de Omar, lo increpa con el calificativo de maldito perro que solo sabe emitir ladridos cuando clama por justicia y el derecho a un abogado.

La privación de la libertad en una celda oscura, diminuta, y el aislamiento del mundo le confirman el estado de enajenación al cual lo van empujando poco a poco con el fin de lograr una declaración de culpabilidad no aceptada por él. El miedo, la soledad, la tristeza, la privación de su dignidad parecen caerle encima con todo el peso del odio impuesto hacia él. En tales condiciones, incluso, llegará a perder la perspectiva del día y la noche, del tiempo transcurrido, mientras espera una salida que parece escaparse paulatinamente.

Cuando se gesta la caída de Ben Larbi, se inicia un camino de perdición para este, acentuado por el hecho de ser acusado sin cargo alguno, bajo la sospecha no comprobada de un complot de terrorismo internacional:

- ¿Cómo? - repuso el detenido en tono rebelde -. Ni siquiera sé cuál es el acta de acusación. ¡Me incriminan de terrorismo internacional así no más! Esta acusación no tiene ni pies ni cabeza. Solo les pido un favor: un juicio de conformidad con el debido proceso de ley de su país, preferiblemente en Nueva York, empezando por permitirme elegir mi abogado, acordándome la presunción de inocencia. No pido lo imposible, señores. (Wabeau, 2015: 266)

La cita anterior pone de manifiesto la semejanza con el proceso impuesto a Josef K. en la novela de Franz Kafka, en la cual, pese a los alegatos de inocencia del acusado, no llega a tener claridad con respecto a los dictámenes impuestos en su contra. Si bien la acusación en el caso de Omar Ben Larbi apunta a actos de terrorismo, lo cierto es que la carencia de objetividad, de justicia, de cargos e indefensión total ponen contra la pared a ambos personajes en sendas novelas.

Por su parte, Omar no renuncia a su razón a pesar de las acusaciones que se 
le asignan. Su proceso arbitrario, si bien lo mina, no lo hace desistir de la verdad, por lo cual rechaza la locura que se desata en los Estados Unidos a raíz de los acontecimientos del 11 de setiembre:

Yo no odio a nadie, señores, ustedes fomentan el odio. Desde el 11 de setiembre han perdido la razón, con su paranoico presidente, y han convertido la noble y libre tierra de América en un país irreconocible. Sospechan de todo el mundo. Todos somos terroristas. Se equivocan, señores. Entiendo su furia y la necesidad de luchar contra el terrorismo, pero sin confundir las cosas. Hay otros métodos. (Wabeau, 2015: 269)

La tortura que se le impone, la cual atenta no solo contra su integridad física, sino que se ve aumentada a partir de la presión psicológica, lo sumerge en la desesperación, pero nunca se muestra derrotado a pesar del encierro y la vejación. En todo momento clama por la lucha justa que sostiene a su manera, a pesar de los obstáculos con los cuales se lo va minando poco a poco. Mientras tanto, carga con la falsa acusación sin posibilidad de recusar los cargos, aun cuando dé sus razones y la verdad en cuanto a lo que se le pregunta. Incluso se le niega la idea de una prosperidad laboral, profesional y económica al frente de una agencia de viajes, como si esta fuese simplemente una máscara para sus verdaderas funciones.

La acusación es producto de una actitud delirante del gobierno estadounidense, incapaz de distinguir entre la verdad y la paranoia, por lo que efectúa cargos infundados a diestra y siniestra. Omar es símbolo de la represión ejercida sobre los suyos. El discurso enfermo y tergiversado de quienes sospechan de él los lleva a crear maquinaciones por parte de Omar y su grupo, que terminan por convertirse en "verdades" que atentan contra Omar Ben Larbi, como cuando revisan sus correos electrónicos y "descodifican" y "codifican" los planes que este lleva a cabo:

¿Te acuerdas de tu extenso mensaje "Letter from a far"? Vamos a leer juntos lo que escribiste sobre las Torres Gemelas: "En efecto, parecen hermanas. Mas todavía no las he observado de cerca. Están en el distrito financiero de Manhattan. Algunos creen que representan a Eva y a Adán, otros piensan que simbolizan el poder económico”. iSon tus palabras, Omar! Continuamos con la lectura: "En todo caso, las Torres Gemelas se ven muy hermosas. Las tengo en mis planes”. ¡Escribiste eso! ¿Qué otra evidencia quieres? Claro está, para desviar nuestra atención, maquillaste el mensaje con palabras confusas en diferentes idiomas, que no son más que códigos dirigidos a tus colegas terroristas. (Wabeau, 2015: 275)

La tortura "velada" que se aplica a Omar y los suyos es el símbolo de la degradación, no solo de estos como presos, sino de la sociedad enfermiza, en pleno malestar, que encuentra fantasmas en cada esquina. Omar sufre ante ello, lo cual lo convierte en una especie de mártir que logra sobreponerse y vivir para contar su experiencia. No obstante, el desánimo que lo va corroyendo lentamente es producto de una situación a la cual no encuentra escape alguno:

De regreso a la intimidad de su celda, se tumbó boca abajo en la cama y estalló en un llanto silencioso e inconsolable, 
hasta que se le hincharon los ojos. Poco después de la cena, curiosamente apagaron la luz. Apenas cayó en un profundo sueño, comenzó una música ensordecedora que venía desde el cielorraso. Le impidieron dormir durante un tiempo imposible de precisar. Se tapaba los oídos con las manos, daba vueltas en la cama y se cobijaba la cabeza, muerto de sueño. Ni siquiera tocaba la comida que le traían como de costumbre. De vez en cuando, apagaban la música, lo dejaban dormir un poco, de pronto reiniciaba el ruido enloquecedor. Aquello era un infierno. Tras mucho tiempo sin dormir, se hallaba en una mezcla entre delirio y realidad. Durante el siguiente interrogatorio, solo se acordaba de que movía la cabeza en signo de aprobación, bostezando, luchando contra el sueño. Además, repetían las mismas preguntas y le parecía que sus respuestas no les interesaban. El déficit de sueño le causó mucha irritabilidad. El interrogatorio lo enervó tanto que llegó a desear regresar a la soledad de su celda. (Wabeau, 2015: 276)

Cuando Omar escribe, cada uno de sus textos enarbola la dignidad de los oprimidos. Sus palabras no son solo las de él, sino las de aquellos que sufren igual o peor condición. Mientras tanto, el sueño americano se desvanece y la lejanía de la familia lo marca por siempre, de acuerdo con lo que apunta el propio final de la novela. La huelga de hambre que lleva a cabo es el grito desesperado de quien clama por justicia. Mientras tanto el mundo parece venírsele encima, alejado de todo, ignorante de dónde se hallaba, con la amenaza de la muerte sobre su cabeza, o el posible traslado a Guantánamo. Con todo ello, defiende su rebeldía hasta el último instante. La fuerza vital que lo anima es, en medio de la barbarie que le corresponde vivir, la que le brinda energía para no renunciar jamás a su discurso de inocencia. El despojo de la libertad física no le impide la asunción de su propio discurso de inocencia y de razón, su razón.

Mientras tanto, con el fin de no matarlo a la espera de una confesión, se ejerce una nueva tortura: obligarlo a alimentarse, cuando se ha declarado en huelga de hambre, por medio de la implantación de mangueras introducidas en su nariz que llevan hasta el estómago. Ello se convierte en un nuevo acto que lo denigra, tal y como lo concibe, mientras la humillación y el dolor lo golpean. Rompen su nariz con la sonda con que lo alimentan e incluso termina por vomitar, mientras de nuevo inician el proceso de alimentación obligatoria. La necesidad de sostenerlo con vida es parte de la tortura que le imponen, mientras el sufrimiento de Omar se vuelve infernal, en medio del frío y en otros momentos de un calor sofocante, en una celda que comparte con otros igualmente inocentes, pero también acusados de terrorismo.

Los interrogatorios se convierten en desgastantes sesiones de preguntas que redundan una y otra vez en los mismos temas con el fin de intentar desentrañar la verdad que lleva consigo Omar. Sus ofensores desfilan como máscaras con el fin de lograr una declaración suya aceptándose como terrorista. Es construido desde este espacio de significación sin posibilidad de demostrar su inocencia. No se trata de lograr una verdad a partir de un interrogatorio, sino de confirmar lo que para ellos es irrefutable. Por ello, Ben Larbi ha sido construido desde el ámbito del terrorista, inculpado sin 
pruebas. De nuevo la novela de Kafka parece gravitar en torno a la culpa asignada desde afuera, sin posibilidad de redención. El proceso aquí no funciona como una causa de conocimiento, sino de confirmación de lo ya instituido desde el opresor. El destino individual y colectivo que podemos encontrar en ambas novelas, también termina por convertirse en un elemento que las une, que las asimila desde la construcción de los personajes, fatídicos y trágicos. En ocasiones, El proceso parece devenir Condenado sin proceso y viceversa. Esto lo reafirma la cita referente a la novela de Kafka, que en nada desdice la insoportable situación en la cual se halla Ben Larbi, aun cuando finalmente pueda encontrar una salida que no lo deja incólume:

Se trata del destino del hombre moderno, protagonista de un proceso que amenaza con conducirlo hacia un futuro - dramáticamente previsto por Kafka - en el cual el ser humano estará a merced de un poder omnipotente, contra el cual no existe la posibilidad de apelación de ninguna clase. Un poder - el Tribunal Supremo de la novela - que se rige por una moral por él mismo impuesta y que se maneja en función de procedimientos esencialmente injustos, deshumanizados y absurdos, cuyo sentido y única explicación es servir de soporte a ese mismo poder. Un círculo vicioso que encierra al hombre esclavizándolo y haciéndole víctima de un sistema cuya única razón es, precisamente, la sinrazón de un esquema social brutal, arbitrario, injusto, en el cual se rompe, haciéndose trizas, la deseada armonía entre el mundo exterior y el mundo interior, espiritual. (en Kafka, 1983: 14)
Josef K. se mueve en un laberinto sin salida. Un poder omnipotente lo controla, lo juzga y lo condena sin que él, protagonista principal de un absurdo proceso, pueda siquiera comprender las circunstancias que lo llevan frente a sus jueces, y mucho menos las leyes y la moral que determinarán el fallo condenatorio. (en Kafka, 1983: 14-15)

La paranoia que inventa terroristas, cuando el terrorismo está del otro lado, en quien intenta asignar este a los otros dejando de lado su propios actos terroristas:

A fuerza de ver sus humildes gestos y de escuchar el soplo de su voz, Omar entendió que era un hombre pobre, se notaba a la simple vista de su rostro y de su boca casi sin dientes. Se quejaba mucho de los abusos de Inter Servicios de Inteligencia (ISI). En su humilde criterio, los gobiernos islámicos no eran buenos, implicaban la miseria para sus pueblos... Lo atraparon por azar cerca de la frontera con Afganistán, lo torturaron para que firmara una declaración. Luego, ISI lo entregó a la CIA para demostrar la plena cooperación del gobierno Pakistaní en la guerra global contra el terrorismo. (Wabeau, 2015: 288)

Es la culpabilidad asignada a pesar de la inocencia. La paranoia gringa parece no tener límites, mientras "encuentra" culpables por doquier. El miedo y otras manifestaciones ideológicas fundamentalistas construyen miedos y culpables, también siembran terror. La asignación de un abogado defensor que es apenas una máscara de quienes lo vigilan para intentar capturar la mayor información a cambio de que confiese, 
se construye también como una manera de desposesión de la cual es totalmente consciente Omar.

Ben Larbi es condenado sin proceso, lo cual remite al título de la novela. Si bien existe el paralelo con la novela de Kafka, ciertamente en esta existe una salida que le permite a Ben Larbi no salir exitoso del todo, pero sí con la libertad de quien no ha cometido crimen alguno. Este final de novela no se manifiesta del todo derrotista, como sí ocurre con la novela del escritor nacido en la antigua Checoslovaquia. A pesar de ello, el último paso representa de igual forma un calvario, antes de hallar la salida a esta muerte simbólica por la cual ha transitado Omar:

El juicio se llevará a cabo sin mí. Prefiero la soledad de mi celda a escuchar sus porquerías. En adelante, si necesitan alguna respuesta mía, solo tienen que volver atrás en sus filmaciones. Si no me permiten un juicio de verdad; o sea, con el derecho de comunicación con mi familia para elegir mis abogados, el acceso a todas las piezas de mi expediente, el contacto con la Cruz Roja Internacional y demás organizaciones de Derechos Humanos, no tengo nada que decirles. Prefiero quedarme callado en mi celda. No tienen ninguna prueba tangible, palpable, real. Se basan en presunciones que no son pruebas. Soy inocente. Estos son mis argumentos. Es la última vez que abro la boca: me declaro en huelga de palabra. (Wabeau, 2015: 293)

En la novela de Kafka, la situación de criminalidad impuesta no dista de la novela de Wabeau: "Alguien debe haber estado vertiendo falsedades con respecto a José K., pues sin que este hubiera hecho nada censurable fue detenido una buena mañana" (Kafka 1983: 17).

Josef K. reclama en torno al procedimiento y la legalidad que median en su captura. Alude a su inocencia, a la falta de cargos, al desconocimiento en relación con la autoridad que ha ordenado su aprehensión, y no recibe respuesta alguna. El paralelo que se manifiesta en ambos textos deja al descubierto la ilegalidad de lo que se conoce como aplicación de justicia. Si bien en El proceso Josef K. nunca es encerrado y privado de libertad, al menos durante la mayor parte del tiempo, como sí ocurre en Condenado sin proceso, ambas acusaciones, sin embargo, no están exentas de arbitrariedad por parte de los ejecutores, verdaderos terroristas y represores, que gozan del favor social para llevar a cabo tales actos.

Por todo lo anterior, la bestialización en la novela de Nacer Wabeau es derivada del proceso de imposición al cual se ve sometido Ben Larbi, que permanece encerrado en una celda poblada de cucarachas, pulgas y demás insectos. En otro momento, es obligado a dormir en la jaula de un perro y allí se lo alimenta, con el fin de obligarlo a hablar, después de declararse en huelga. En esa condición se da cuenta de que no puede llegar más abajo en la escala de la degradación. Solo espera su muerte como salida única. Se refieren a él como perro y lo obligan a actuar como tal. Lo desincorporan de su condición y lo reducen por completo, hasta denigrarlo como ser humano.

En medio de todo esto, la peor tortura que se gesta sobre él responde al hecho de ser torturado, vejado, degradado, bestializado, sometido a los peores tratamientos, a pesar de no existir una acusación en su contra. Ello le da 
la noción del infierno al cual es sometido, sin poder liberarse de lo que esto representa. La angustia de verse sometido a un juicio injusto, sin cargos reales en su contra y con el riesgo de una condena perpetua, lo convierte en un hombre al borde de la derrota, con la añoranza de una familia a la que quizás no vuelva a ver, sin la posibilidad ni siquiera de despedirse de esta.

Finalmente, cuando por fin es liberado, se establece la distancia con respecto al texto de Kafka, en tanto en la novela del checo no existe posibilidad de escape, aun cuando sea inocente:

- No cabe duda alguna - prosiguió K. en voz muy baja, emocionado por la enorme atención de que le hacía objeto la asamblea: en medio del silencio se dejaba oír un zumbido aún más estimulante que los atronadores aplausos; de que detrás de las diligentes obras de esta justicia, es decir, detrás de la detención, y hoy, en mi caso, detrás del interrogatorio, existe y trabaja una gran organización, organización que no solo utiliza agentes corrompidos e inspectores idiotas y jueces de instrucción de quienes lo mejor que se puede decir es que reconocen sus propias limitaciones, sino que, además, disponen de una alta jerarquía social con su indispensable y numeroso séquito de criados, escribientes, policías y otros auxiliares, quizás inclusive verdugos, y no rehuyo esta palabra. ¿Y cuál es el significado de esta gran organización, caballeros? Es acusar de delitos a personas inocentes, entablar contra ellas procesos disparatados, la mayoría de las veces, es cierto, sin resultado alguno, como sucede en mi caso. (Kafka, 1983: 63)
El infierno para K. no tiene escapatoria, y la condena es el camino irreversible de un castigo impuesto a partir de un crimen desconocido, lo cual vuelve, en definitiva, más insoportable su pena. Es ello lo que recibe en las palabras de Leni, personaje femenino que intenta "aconsejarlo" para que se declare culpable. De nuevo la relación con Ben Larbi y la exhortación a su culpabilidad encuentran asidero:

Por favor, no me pida nombres. En lugar de eso tome en serio mis consejos y no sea tan terco. No se puede luchar contra el tribunal, debe usted confesarse culpable. Haga su confesión en la primera oportunidad que se le presente. Hasta que no lo haga usted, no tendrá ninguna oportunidad, ninguna, de escapar de sus garras. (Kafka, 1983: 130)

En la novela de Wabeau, no obstante, Ben Larbi sí logra ser liberado; queda marcado, tal y como él lo señala, por pesadillas y una reputación que debe reconstruir ante el mundo. Su sueño de triunfo se esfuma, pero logra reencontrarse con la familia y ello representa rehacerse a su manera, empezar de cero y recobrar su condición de dignidad y respeto. El paso de ser un hombre enterrado vivo, como él mismo lo dice, a regresar a su patria, reencontrarse con los suyos y empezar de nuevo es revivir, trazar nuevos objetivos a su vida y luchar por un Argel libre y grande, por una tierra próspera y llena de sueños, como él.

Ben Larbi y Joseph K. son juzgados desde la presuposición de una culpabilidad asignada pero no comprobada. Cada uno reclama su derecho a una liberación que no llega de igual forma para ambos: dolorosa para Ben Larbi, imposible para Joseph K. 
Joseph K. está marcado por un juicio sin salida, derrotado y juzgado de previo. Su salida es la derrota total. $\mathrm{Su}$ escapatoria es imposible, no existe salida para su proceso. La crítica al mundo en general, culpable de su condena, a pesar de la inocencia que defiende para sí, es parte de la derrota existencial que carga sobre sus hombros. K. es un condenado a muerte derrotado por siempre:

- No - dijo el capellán-, pero temo que terminará mal. Te tienen por culpable. Es posible que tu proceso no pase nunca de la jurisdicción de un tribunal inferior. Al menos por ahora se da por probada tu culpabilidad.

- ¡Pero yo no soy culpable! - dijo K. -. Es un error. Y si vamos a eso, ¿cómo calificar a un hombre de hombre de culpable? Aquí todos somos simplemente hombres, tanto el uno como el otro. (Kafka, 1983: 240)

La defensa de ambos personajes en estas novelas pasa por el filtro de una carencia total. Los abogados parecen formar parte de un sistema que juega en contra de la inocencia de los acusados. Cada uno de los procesos es un camino hacia la condenatoria final. Las defensas de estos no ejercen con fuerza su cargo y engañan con palabras de espera a cado uno de sus defendidos. Ben Larbi recrimina finalmente, lo mismo que K., cuando descubre la falsedad de una seudoayuda que en verdad no funciona y de manera deliberada. La justicia que debe darse para ambos no llega a materializarse de la mejor manera, ni siquiera en el caso de Ben Larbi, quien finalmente es liberado, no sin pasar por vicisitudes y vejámenes por los cuales nadie responde en definitiva.

Finalmente, la derrota acompaña el acontecer de ambos. Si bien Ben Larbi alcanza finalmente la libertad, la forma en la cual sale termina debilitándolo ante los demás, con la sospecha de una libertad no total. Joseph K., por su parte, no logra evadir "la justicia" aplicada por el sistema y encuentra el encierro como llegada final de su vida. La pesadez de un sistema social ingrato e injusto termina por derrotar y avasallar los esfuerzos de ambos, aun cuando, insistamos, el final no es precisamente equivalente para ambos personajes.

\section{Bibliografía}

Bassnett, Susan. Comparative literature: a critical introduction. Oxford, U.K., Blackwell, 1993.

Brunel, Pierre e Yves Chevrel (editores). Compendio de literatura comparada. México, Editorial Siglo XXI, 1994.

Domínguez, César, Haun Saussy y Darío Villanueva. Introducing comparative literature: new trends and applications. Londres, Routledge, 2015.

Gnisci, Armando (editor). Introducción a la Literatura Comparada. Barcelona, Editorial Crítica, 2002.

Kafka, Franz. El proceso. Cuarta edición. México, Editores Mexicanos Unidos, 1983.

Krysinski, Wladimir. Comparación y sentido: varias focalizaciones y convergencias literarias. Lima, Universidad Católica Sedes Sapientiae, 2006.

Wabeau, Nacer. Condenado sin proceso. San José, Editorial Uruk, 2015. 